\title{
Labor periodística del camagüeyano Luis Suardíaz Rivero en medios impresos durante el periodo 1959-2005
}

\section{Journalistic Performance of the Camagüeyan Luis Suardíaz Rivero in Print Media during 1959-2005}

Lesvia Amelia Prieto Valdivieso (Cuba)

Universidad de Camagüey

lesvia.prieto@reduc.edu.cu

Karla Gómez Gonzólez (Cuba)

Universidad de Camagüey

karla.gomez@reduc.cu
Daymisi Contreras García (Cuba)

Universidad de Camagüey

daymisi.contreras@reduc.cu

Marcelo Chacón Reyes (Cuba)

Universidad de Camagüey

marcelo.chacon@reduc.edu.cu

\section{Resumen}

El presente artículo de revisión tiene como propósito el análisis de la historia de un periodista insigne de Camagüey, sobre todo en su accionar

\section{Abstract}

This review article analyzes the history of a famous journalist in Camagüey, with respect to his critical, journalistic, and literary action. In spite of his valuable

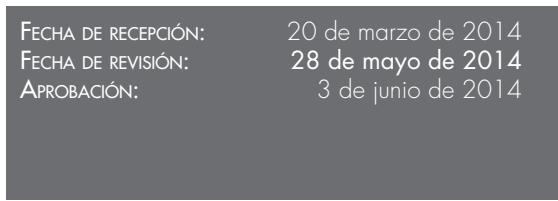

FECHA DE RECEPCIÓN:

FECHA DE REVISIÓN:

APROBACIÓN:
28 de mayo de 2014

3 de junio de 2014
Para Citar este artículo / to Cite this ARTICle

Prieto Valdivieso, L. A.; Gómez González, K.; Contreras García, D. y Chacón Reyes, M. (2014). Labor periodística del camagüeyano Luis Suardíaz Rivero en medios impresos durante el periodo 1959-2005, Poliantea, 10(18), pp. 179-202. 
crítico literario-periodístico. A pesar de su valiosa trayectoria como profesional de la prensa, aún se constata un déficit bibliográfico que enmarque su desempeño en ese sentido y los estudios académicos solo reflejan su labor como poeta. En busca de solucionar este problema, se plantea como objetivo general la caracterización de los aspectos de la crítica literaria periodística de Luis Suardíaz en la etapa antes mencionada. Se trata de una investigación de perspectiva cualitativa, con un diseño transeccional y descriptivo. Además, se inserta como un estudio de corte histórico, comunicológico. Como método principal se emplea el biográfico, también se refieren los métodos teóricos, análisis históricológico, análisis-síntesis e induccióndeducción, así como las técnicas entrevista en profundidad, observación participante, análisis de contenido y, del nivel cuantitativo, la investigación documental. Expresa como resultado la presentación de "apuntes de la historia de vida de Luis Suardíaz Rivero" y un análisis de su obra como crítico literario siguiendo novedosas categorías de análisis.

Palabras clave: labor periodística, crítico literario, periodismo cultural, método biográfico. professional trajectory in the press, there is still not enough bibliography to frame his performance in this area, and the academic studies found reflect only his work as a poet. In order to solve this problem, we set as the main objective the characterization of the aspects related to the literary critic of Luis Suardíaz in the period previously mentioned. This is not only a qualitative research with a descriptive design, but also a historical and communicative study. The main method used was biographical, but we also made reference to theoretical methods such as: the historical-logical analysis, the analysis-synthesis model, and the induction-deduction approach. In addition, we used in-depth interview, participant observation, content and quantitative level analysis, as well as documentary research techniques. The result was the presentation of 'notes regarding the life of Luis Suardíaz Rivero' and an analysis of his work as a literary critic by following new analysis categories.

Keywords: journalistic performance, literary critic, cultural journalism, biographic method. 


\section{Labor periodística del camagüeyano Luis Suardíaz Rivero en medios impresos durante el periodo 1959-2005}

\section{Journalistic Performance of the Camagüeyan Luis Suardíaz Rivero in Print Media during 1959-2005}

Lesvia Amelia Prieto Valdivieso (Cuba)

Universidad de Camagüey

lesvia.prieto@reduc.edu.cu

Karla Gómez Gonzólez (Cuba)

Universidad de Camagüey

karla.gomez@reduc..u
Daymisi Contreras García (Cuba)

Universidad de Camagüey

daymisi.contreras@reduc.cu

Marcelo Chacón Reyes (Cuba)

Universidad de Camagüey marcelo.chacon@reduc.edu.cu

\section{Introducción}

"La historia anda por el mundo con careta de leyenda. No hay que ver solo a las cifras de afuera, sino levantarlas, y ver, sin deslumbrarse, a las entrañas de ellas". José Martí, héroe nacional de Cuba, manifiesta en sus palabras la relevancia de estudiar la historia que, sin duda, se compone de hechos trascendentales. Y qué son los hechos, si no una acción desarrollada por un hombre u hombres de fuerte voluntad y espíritu.

La historia es una ciencia que estudia e interpreta los hechos más importantes del pasado humano, examinados de acuerdo con sus vestigios. 
Concretamente, el campo de estudio de la historia serán todos aquellos acontecimientos que por su trascendencia en determinado tiempo y espacio han alterado o modificado el modo de vida de alguna sociedad en cualquiera de sus aspectos: social, económico, político, religioso.

La reflexión anterior es de gran utilidad para comprender mejor nuestro contexto social actual. Por lo tanto, es innegable la importancia de los estudios históricos en el panorama mundial, dado que la historia es un argumento necesario para influir en decisiones futuras.

Sin embargo, a pesar de la trascendental importancia que tiene la historia en lo macro, los aspectos individuales reflejan una singular importancia, porque constituyen un elemento indispensable para la preservación de la memoria histórica de los pueblos. Por eso, en ese sentido, el estudio de personalidades constituye un eslabón determinante para la concepción de la historia.

Desde épocas remotas, ha existido la necesidad de analizar la vida de grandes personas, pero no es hasta el siglo XX, con la escuela de Chicago, que los estudios de historia de vida cobraron auge dentro del movimiento indigenista de la década de 1940 que tuvo como máximo precursor al antropólogo estadounidense Oscar Lewis.

Dentro del contexto latinoamericano, se destacan por sus aportes en esta materia el colombiano Gabriel García Márquez (1927-2014), el uruguayo Eduardo Galeano (1940), el brasileño Jorge Amado (1912-2001), entre otros, además del periodista y escritor cubano Jaime Sarusky (1931).

El decursar de los años trajo la década de 1960, la cual sumó a esta temática una línea cualitativa, y como referencia de esta etapa se pueden citar las obras del cubano Miguel Barnet (1940): Biografía de un cimarrón (1966), Canción de Rachel (1969), Gallego (1983) y La vida real (1986). A esos esfuerzos se unen los trabajos investigativos de Luis Eduardo Álvarez Álvarez, con Circunvalar el arte, y la historia de vida de Conchita Fernández (2001), de Pedro Pablo Prada.

Dentro del contexto puramente periodístico, esta arista de investigación cualitativa adquiere singular trascendencia, y como ejemplo pueden enmarcarse las historias de vida de Ciro Bianchi (2009), Luis Rogelio Nogueras (2009), Eddy Martin (2010); entre otras situadas en el contexto camagüeyano, figuran los estudios realizados a los periodistas 
Manuel Márquez Sterling (2001), por María Socarrás y María Delys Cruz; a Mary Cruz (2007), por Sadiel León; a Francisco Prendes Mederos (2009), por Yamilka Rodríguez González; a Sergio Canales Selpa (2010), por Luz Yamila Rojas Meneses, y a Roberto Agudo (2011), por Sheila Delgado Guerra.

Después de ahondar en estos antecedentes académicos, es preciso destacar la labor de Luis Suardíaz dentro del periodismo, específicamente como crítico literario, ya que desde 1959 ha incursionado en varios medios de prensa, como periódicos, revistas especializadas, radio y agencias de información. Además, es merecedor de disímiles premios y condecoraciones que distinguen su labor como periodista, entre los cuales puede destacarse el Premio Nacional de Periodismo Cultural Juan Gualberto Gómez y el Premio Nacional de Periodismo José Martí.

Sin embargo, aún existe una escasa información sobre esta faceta de su labor profesional y los estudios académicos sobre su obra se circunscriben solo a su quehacer poético.

A pesar de la necesidad de acometer estudios históricos que respondan a estas características, y de la importancia de la personalidad en cuestión para el periodismo cubano, aún se constata un déficit bibliográfico que evidencie su trascendencia periodística como crítico literario.

La investigación se propone como objetivo general caracterizar la labor periodística de Luis Suardíaz Rivero en medios impresos durante el periodo 1959-2005.

\section{Material y métodos}

El estudio corresponde, preferentemente, a una perspectiva metodológica cualitativa, aunque no se obvian técnicas de corte cuantitativo que permiten un conocimiento más profundo acerca del desempeño de la personalidad objeto de estudio.

No obstante, la tipología preferencial es la cualitativa porque permite describir determinado contexto social, motivaciones y actitudes desde una óptica subjetiva. Además se estudia la obra de Luis Suardíaz en su singularidad y, para ello, es necesario adentrarse en la profundidad de los datos y no en su frecuencia.

También, este estudio investigativo se corresponde con un diseño del tipo no experimental, al no incluir variables. Se trata, en este caso, de una investigación secuencial (propia de un diseño cualitativo), donde las categorías de análisis no se manejan 
porque ya han sucedido, sino que se ordenan en el tiempo, a partir de la observación de las relaciones establecidas entre ellas, tal y como se han dado en su contexto natural.

Igualmente, en la clasificación de diseños no experimentales, se ubica en el tipo transeccional, pues los datos fueron recolectados en el periodo seleccionado para el estudio: 1959-2005.

Por ende, la presente investigación es descriptiva, porque pretende caracterizar la labor de Luis Suardíaz Rivero como sujeto de la comunicación desde 1959 hasta 2005, para especificar sus propiedades, rasgos o tendencias de su actividad profesional.

Los métodos teóricos empleados fueron análisis y síntesis, inducción y deducción y análisis histórico-lógico. Estos métodos cumplieron funciones gnoseológicas determinadas, por lo que en el proceso de realización de la investigación se complementaron entre sí.

El método análisis-síntesis se emplea como punto de apoyo para la concepción del marco teórico, en busca de procesar la información consultada en las diferentes referencias bibliográficas. De igual manera, la utilización del análisis posibilita una mayor comprensión de los datos obtenidos acerca de la vida profesional del periodista, para luego ser utilizados de forma sintética.

De ahí la siguiente definición del método, que se caracteriza por "descomponer mentalmente la realidad en sus partes [...] [a la vez que] establece la unidad entre las partes y reconstruye el todo" (Pérez y Nocedo, 1983, p. 78).

En específico, el método histórico-lógico establece el estudio y los antecedentes de los fenómenos objeto de investigación en su devenir histórico, a la vez que se delimitan cuáles son las leyes generales del funcionamiento y desarrollo del fenómeno.

En este caso, el empleo de este método para la investigación posibilita una mayor comprensión del desempeño periodístico de Luis Suardíaz desde una etapa que refleja la relevancia de su labor profesional, teniendo en cuenta su trayectoria dentro del periodismo cultural y específicamente su desempeño como crítico literario.

Finalmente, el método inducción-deducción permite la conformación del estudio, ya que el razonamiento inductivo posibilitó crear definiciones generales a partir del desglose de las categorías de análisis, mientras que la deducción sirve de base para la construcción de 
la historia expuesta en esta investigación. Según este planteamiento, con la inducción-deducción, se establece un "enlace objetivo de lo singular y lo general en la realidad misma" (Pérez y Nocedo, 1983, p. 80).

Dentro del estudio cualitativo prima el método biográfico, en busca de "explorar la dinámica de situaciones concretas por medio de la percepción y relato que de ella hacen sus protagonistas" (Rodríguez, 2004, p. 57).

Por ende, dentro de este método se escoge la tipología de historia de vida partiendo de la premisa que justifica que

... la historia de vida tiende a la exhaustividad, y se suelen además emplear otros documentos o testimonios que corroboren o amplíen la información recogida. Esta posibilidad se utiliza cuando disponemos de un relato biográfico excepcionalmente rico y que corresponda a un sujeto realmente singular (Meneses y Cano, 2008, p. 4).

En este sentido, se pretende recopilar información apelando a la memoria y el grado de cercanía que tuvieron los informantes clave con la personalidad en cuestión, para crear diferentes juicios; por lo tanto, es una historia de vida de relatos cruzados, los cuales posibilitan la triangulación de los datos.

El procedimiento clave para obtener los datos requeridos es la historia oral, dado que "a la cultura pertenece todo un arsenal de saberes que se transmiten por la vía de la comunicación interpersonal" (Vera, 2000, p. 219).

Como una de las técnicas de mayor preponderancia se utiliza la entrevista en profundidad, en vista de que "se desarrolla a partir de cuestiones que persiguen reconstruir lo que para él -el entrevistado- significa el problema objeto de estudio" (Rodríguez, Gil y García, 2008, p. 168).

En efecto, se emplea esta técnica en busca de testimonios de personas que se relacionaron con Suardíaz en determinada época de su vida y tengan la capacidad narrativa para que al investigador le posibilite reconstruir historias pasadas. De esta manera, la investigación adquiere cierto valor humano, porque puede recopilar juicios y criterios que tengan los entrevistados acerca de la labor periodística del sujeto en cuestión.

Las entrevistas corresponden a la tipología de semiestructuradas para incluir posibles argumentos, no 
previstos con anterioridad, que surgieran en el transcurso de la entrevista. Para ello, se seleccionaron de manera intencional tres segmentos de entrevistados. Sujetos tipo A (compañeros de trabajo), sujetos tipo $B$ (amigos cercanos) y sujetos tipo $\mathrm{C}$ (familiares):

- Sujetos tipo A: compañeros de trabajo: $\mathrm{n}=3$.

Para la delimitación de este segmento, se tienen en cuenta aspectos tales como:

- Disposición y capacidad para brindar información.

- Haber trabajado con el periodista en cuestión por un periodo mínimo de un año.

- Haber coincidido con el sujeto objeto de análisis al menos en un medio de comunicación.

- Tener al menos cinco años de experiencia en el desempeño de la labor periodística.

- Sujetos tipo B: amigos cercanos: $\mathrm{n}=2$.

Para la selección de este grupo, se tienen en cuenta los siguientes factores:
- Disposición y capacidad para brindar información.

- Grado de proximidad de al menos cinco años con la personalidad en cuestión.

- Reconocimiento de la amistad por parte de los compañeros de trabajo y miembros de la familia.

- Sujetos tipo C: familiares: $\mathrm{n}=1$. En este segmento, se incluye a aquel familiar que se corresponda con el siguiente criterio de selección:

- Disposición y capacidad para brindar información.

- Cercanía afectiva.

- Nivel de conocimiento acerca de la labor periodística de la personalidad.

En cuanto a la elección de los informantes clave, se seleccionaron a dos entrevistados, para contrastar respuestas y confirmar datos valiosos acerca de la vida de la personalidad.

Según el criterio de elección, fueron incluidos dentro de este grupo: Elisa Masiques, esposa de Suardíaz y principal fuente de información para la obtención de cualquier dato relacionado con los textos periodísticos de la personalidad objeto de estudio, así como para obtener información 
acerca de sus amigos y compañeros de trabajo más cercanos; además de experimentar personalmente, a partir de 1963, cada una de las vivencias profesionales de la personalidad.

El otro informante clave es Manuel Villabella, periodista camagüeyano con un relevante desempeño dentro de la esfera cultural y amigo del periodista en cuestión, elegido por su vital contribución para corroborar información acerca del quehacer periodístico de Suardíaz en Camagüey, su provincia natal.

La elección de los informantes clave se realizó atendiendo a los siguientes criterios de selección:

- Profundo conocimiento de la labor de Suardíaz como periodista cultural.

- Conocimiento de las relaciones sociales de la personalidad objeto de estudio.

Otra técnica empleada durante el proceso investigativo fue la observación participante que no es más que "un registro sistemático, válido y confiable de comportamientos o conducta manifiesta" (Baptista, Hernández, C. C. y Hernández, R. S., 2010, p. 327).

La técnica fue aplicada en el periodo de un mes y medio, en la casa de la personalidad objeto de estudio, para examinar el ambiente y las relaciones familiares, las cuales se desarrollaron de manera favorable.

La aplicación de este instrumento investigativo permitió un cambio de papel por parte de la investigadora, para desdoblarse y suplir el papel de observador por el de participante.

Luego de aplicar la observación participante, como máximo resultado de la investigación se pudo comprobar el nivel de compromiso que tiene la familia de Suardíaz con todo el legado intelectual de esta personalidad, lo cual se evidencia en una extensa recopilación de todos sus trabajos periodísticos: grabaciones para programas radiales, entrevistas realizadas a la personalidad, correspondencia, autobiografías y otros documentos laborales ubicados en fichas bibliográficas y estrictamente guardados en una biblioteca familiar.

Además, para lograr un acercamiento total a la vida del periodista Luis Suardíaz fue necesario un análisis del material bibliográfico existente como parte de la aplicación de la técnica investigación documental bibliográfica.

En este caso, es válido afirmar que la "la investigación documental es una técnica siempre utilizada en 
una investigación científica e incluso puede constituirse en el método principal empleado" (Alonso y Saladrigas, 2012, p. 69).

De este modo, fue preciso el análisis de documentos que validan el accionar periodístico de la personalidad objeto de estudio, como publicaciones impresas, grabaciones para programas de radio y entrevistas realizadas a dicha personalidad.

También fue pertinente la revisión de diferentes materiales personales, entre los que se incluyen: autobiografías, evaluaciones profesionales, correspondencia, premios, conferencias y fotos.

La revisión bibliográfica de todo este material solo fue posible mediante la exploración del archivo personal de Suardíaz donde existe una extensa recopilación de los trabajos periodísticos de este autor.

Se revisan 200 críticas y perfiles de escritores, artistas y personalidades, escritos en medios de prensa nacionales: 185 en el periódico Granma, 8 en la revista Bohemia, 2 en la revista Unión, 2 en la Nueva Gaceta, 1 en Arte y Literatura, 1 en Prensa Libre y 1 en Revolución y Cultura.

Aunque es válido aclarar que Suardíaz escribió más trabajos periodísticos dentro de la esfera cultural, pero no figuran como textos que respondan a las características de la crítica literaria que se explicitan en este trabajo de diploma. Además, los artículos fueron seleccionados por estar enmarcados en el periodo en que se estudia a la personalidad, de 1959 a 2005, y presentar un buen estado de conservación.

También fueron consultados 26 documentos, entre los que figuran cartas, cronologías, autobiografías, premios, y otros objetos personales.

Los centros de documentación determinados para la revisión fueron:

1. Para la dimensión crítica literaria periodística:

a. Páginas culturales de periódicos y publicaciones especializadas.

- Un artículo en Arte y Literatura, página cultural del periódico Adelante.

- Objetivo: corroborar el desempeño de Suardíaz como crítico literario en 1960.

- Lugar: archivo personal de Suardíaz, documentación de la página cultural Arte y Literatura, perteneciente al periódico Adelante.

- Un artículo en el diario Prensa Libre. 
- Objetivo: indagar acerca de la labor de Suardíaz como crítico literario en 1960.

- Lugar: archivo personal de Suardíaz, documentación del diario Prensa Libre.

- Un artículo en Revolución y Cultura.

- Objetivo: obtener información acerca del accionar de Suardíaz como crítico literario en 1974.

- Lugar: archivo personal de Suardíaz, documentación de Revolución y Cultura.

- Ocho publicaciones en la revista Bohemia.

- Objetivo: investigar acerca del desempeño de Suardíaz como crítico literario en el periodo 1976-1980.

- Lugar: archivo personal de Suardíaz, documentación de la revista Bohemia.

- Dos artículos en la revista Unión.

- Objetivo: indagar acerca de la labor crítica literaria periodística de Luis Suardíaz en 1983 y 1985, así como distinguir los textos merecedores del Premio Nacional de Crítica Literaria Mirtha Aguirre.
- Lugar: Biblioteca Provincial Julio Antonio Mella.

- Dos artículos en Nueva Gaceta, periódico mensual de la Unión de Escritores y Artistas de Cuba (Uneac).

- Objetivo: investigar acerca del desempeño de Suardíaz como crítico literario en 1984.

- Lugar: archivo personal de Suardíaz, documentación de la Nueva Gaceta.

- Ciento ochenta y cinco publicaciones en el periódico Granma.

- Objetivo: obtener información acerca del accionar de Luis Suardíaz como crítico literario en el periodo 1991-2004.

- Lugar: archivo personal de Suardíaz en formato digital.

2. Tesis:

- Trabajo de diploma: El periodismo cultural en el suplemento cultural de la Televisión Cubana (TVC), del autor Jorge Luis Rodríguez González, La Habana, 2007.

- Objetivo: indagar acerca de los elementos teóricos que sustentan al periodismo 
cultural como una especialidad del quehacer periodístico.

- Lugar: Biblioteca de la Facultad de Comunicación de la Universidad de La Habana.

- Trabajo de diploma: La crítica literaria sobre la narrativa cubana de los años 80 en La Gaceta de Cuba, de Laura Elena Pérez Cerito, La Habana, 2008.

- Objetivo: investigar acerca de los elementos teóricos que avalan la crítica literaria como una especialidad del periodismo cultural.

- Lugar: Biblioteca de la Facultad de Comunicación de la Universidad de La Habana.

3. Entrevistas:

a. Entrevista a Pedro García, periodista de la Agencia de Información Nacional (AIN).

b. Entrevista a Rolando Pérez Betancourt, periodista de la página cultural del diario Granma y crítico cinematográfico.

c. Entrevista a Jorge Barata, periodista de Prensa Latina.

d. Entrevista a Ángel Peláez, jubilado y antiguo compañero de
Suardíaz en la dirección de Propaganda del Movimiento 26 de Julio en Camagüey.

e. Entrevista a Gilberto Mediavilla, jubilado e interventor del periódico Prensa Libre en 1960.

f. Entrevista a Mireya Suardíaz Masiques, hija de Luis Suardíaz y Elisa Masiques.

- Objetivo: buscar opiniones acerca del desempeño de Suardíaz como crítico literario en las etapas seleccionadas.

- Lugar: casa de los entrevistados, Casa de los Combatientes en Camagüey e Instituto Cubano de Radio y Televisión (ICRT).

4. Otros documentos personales:

a. premios

b. reconocimientos

c. condecoraciones

- Objetivo: investigar sobre el accionar de Suardíaz como crítico literario durante toda su vida profesional (1959-2005).

- Lugar: archivo personal de Suardíaz.

5. Documentos inéditos:

a. Datos laborales de Luis Suardíaz.

- Objetivo: recopilar datos acerca del desempeño 
de Suardíaz como crítico literario en la etapa de 1959-2005.

- Lugar: archivo personal de Luis Suardíaz.

Independientemente de que en todo el proceso de investigación prevalezca la perspectiva cualitativa, es necesario acogerse en determinado momento al análisis de contenido, técnica cuantitativa que, por su importancia para la elaboración de este estudio, no puede obviarse.

"Es un método de investigación que se dedica a la descripción objetiva, sistemática y cuantitativa del contenido manifiesto de la comunicación" (Kerlinger, 1986, p. 41). De este modo, el análisis de contenido permite la revisión de textos periodísticos redactados por Luis Suardíaz Rivero.

El análisis de contenido fue aplicado a los artículos de Suardíaz publicados en medios de comunicación impresos nacionales entre 1959-2005 y que respondieran a las características específicas de la crítica literaria periodística (anexo 9).

Para realizar el estudio se utiliza la categoría labor periodística:

Entendida como el desempeño de un profesional que, además, de comunicar la realidad, a través de la prensa escrita, radial, televisiva y digital tiene la posibilidad de pensarla social y éticamente, valiéndose de perspectivas transdisciplinarias, con clara conciencia de su papel como trabajador de la esfera política, ideológica y cultural, con curiosidad universal, espiritual, de investigación; pasión por comunicar correctamente, de modo veraz, sugerente y apelativo (Rodríguez, 2009).

Por consecuencia, se traza como dimensión la crítica literaria periodística:

La crítica literaria periodística es un discurso secundario en el sentido [de] que tiene como objeto de conocimiento los textos literarios. Está constituida por estrategias o metodologías de interpretación que operacionalizan secuencias de procedimientos seguidos para comentar un texto literario previamente existente... la crítica literaria periodística es descriptiva e interpretativa, es desarrollada esencialmente por los periodistas culturales e implica una evaluación coyuntural conectada con el presente de la enunciación del texto (Manuel Santiago, 2005). 
Por su parte, los indicadores fueron:

- Géneros literarios.

- Modalidades literarias.

- Recursos estilísticos.

Luego de esbozados los objetivos generales y específicos, así como los métodos y técnicas de investigación empleados, fueron determinadas para la conformación de la historia de la personalidad en cuestión- dos etapas que enmarcan el desempeño de Luis Suardíaz como crítico literario:

- Primera etapa: 1959-1984. Esta primera etapa en la labor profesional de Luis Suardíaz Rivero se corresponde con su formación periodística, donde se evidencia su desempeño a inicio del triunfo de la Revolución en medios provinciales como Orientación Revolucionaria y Adelante.

- Segunda etapa: 1984-2005. El correspondiente segmento de años corresponde a su quehacer periodístico en Prensa Latina, el diario Granma y emisoras radiales como CMBF y Radio Progreso, además de evidenciar su prolífera obra como crítico literario.
Como unidad observable humana, se seleccionó al periodista Luis Suardíaz Rivero por su notable contribución al periodismo cultural cubano, durante el periodo 1959-2005, accionar que amerita una investigación que refleje su desempeño como periodista.

Por otra parte, el muestreo es de tipo intencional no probabilístico y responde a la característica de sujeto tipo. Además, la elección de los informantes se enmarca como una selección intencional, dinámica y secuencial.

La delimitación de los informantes clave respondió a los siguientes criterios:

- Informantes clave: se seleccionaron dos informantes de acuerdo con el nivel de conocimiento que tienen del tema y el grado de compromiso con la investigación. Además, se tuvo en cuenta la disposición de estas personas para brindar información, así como la coherencia y profundidad en sus respuestas.

- Casos extremos: para la elección de los tres informantes se tuvo como referencia ciertas características, como un elevado conocimiento sobre la crítica literaria 
de Luis Suardíaz en la etapa seleccionada para la investigación.

También fueron referentes muestrales todos los documentos personales encontrados en el archivo de la casa de Suardíaz, entre los cuales se incluyen autobiografías, premios, fotos, grabaciones y audiovisuales.

\section{Resultados}

Elementos que distinguen la labor periodística de Luis Suardíaz Rivero como crítico liferario

La crítica literaria de Luis Suardíaz se enmarca en dos periodos: el primero de 1959 a 1983 y el segundo de 1984 a 2005. Como resultado del análisis de contenido, se puede precisar que, desde la década de 1960, en la cual empieza a formarse su crítica literaria periodística, la personalidad objeto de estudio demuestra una preferencia por abordar, entre otros géneros, temáticas literarias enfocadas en los subgéneros: poesía, novela y ensayo, así como una inclinación por tratar aspectos relacionados con el autor, el libro y la literatura.

Con respecto a la etapa posterior, que se circunscribe como un periodo de realce de su crítica literaria, se observa una notable diferencia. Primeramente en cuanto a la cantidad de artículos publicados, ya que en el primer periodo se pudo constatar la existencia de 10 textos que responden a las características específicas de la crítica literaria, de ellos, seis responden a la modalidad literaria de autor, especializados en el subgénero poesía; tres dedicados a la literatura poética y solo uno se refiere a una publicación en específico, que en este caso se trata de la revista especializada Unión, por lo cual no se puede definir en este texto la existencia de un subgénero, pues se trata de una publicación heterogénea.

Definitivamente, puede caracterizarse como un periodo de formación de su estilo periodístico en cuanto a la redacción de los textos críticos. Es aquí donde comienza a perfilarse, en su obra, la preferencia estilística de citar en el titular el nombre del autor, lo cual permite un acercamiento inmediato al contenido del texto.

Todo el grueso de sus críticas, redactadas desde 1959 hasta 1983, está destinado a publicaciones nacionales, pero no tienen un carácter sistemático, es decir, pueden definirse como colaboraciones esporádicas, además no se ajustan a un determinado medio de prensa.

La aplicación de la revisión bibliográfica documental le permitió a la 
autora percibir que la redacción de las críticas literarias se concibe, en periodismo, como una subespecialización, por lo que es considerado un trabajo de rigor en cuanto a contenido y forma.

Por lo tanto, el escritor de la crítica literaria periodística debe tener ciertas características que le posibiliten la realización de un trabajo de tal magnitud. Suardíaz era literato y periodista, lo cual influye en la redacción de las críticas literarias. "Es sumamente difícil para el poeta crítico impedir que sus propios gustos que están íntimamente vinculados con su propia práctica se conviertan en una ley general de la literatura" (Frye, 2001, p. 110).

Pero la crítica de Suardíaz carece de juicios demasiado subjetivados y superfluos que no transmitan una percepción total y cabal de la obra en cuestión.

No se trataba de una crítica literaria de corte científico, sino valorativo, esencialmente es una valoración sencilla, destinada al amplio público que debe leerlo, por lo tanto, no contiene una forma estética, sino preferencialmente divulgativa. De este modo, en su obra crítica se evidencia cierta intencionalidad para cambiar el gusto artístico de las grandes masas.

Además, aplica la labor orientadora, al dirigir la lectura del lector medio hacia los siguientes aspectos: ¿cómo leer a un escritor determinado?, ¿qué apreciar en la obra del autor?, ¿cuáles elementos de identidad, política, artística o propiamente estética posee la obra?

Aunque en sus textos no se pueda constatar la existencia de algún trabajo referido a la lectura como modalidad literaria, en cada uno de sus textos críticos se perfilan implícitamente técnicas y métodos para la lectura.

No es hasta 1984 que puede hablarse de un periodo de mayor madurez en la crítica literaria periodística de Suardíaz; es aquí que se puede hacer referencia a un antes y un después en sus trabajos. Precisamente en ese año recibe el Premio Nacional de la Crítica Literaria Mirtha Aguirre por la obra Tres poetas de la Revolución, que publicó la revista Unión, artículo dedicado a los escritores Agustín Gómez-Lubián Urioste, Rolando Escardó y José Álvarez Baragaño (resultado del análisis de contenido).

Son tres jóvenes escritores cubanos que, independientemente de los avatares de sus vidas y las frustraciones ocasionadas por el ideal revolucionario, tenían en común la juventud, la lucha por la causa del pueblo y una muerte a temprana edad. 
Entre lo reseñado y comentado, Suardíaz conjuga experiencias personales de los poetas, influencias literarias, vivencias en relación con la escritura de cada uno de los versos, así como sus cualidades físicas y morales que los distinguían en el pasado.

El decursar de años ha borrado injustamente el recuerdo de estos escritores en la memoria de su público, toca entonces al crítico recurrir a los recursos lingüísticos de la profesión reporteril para, entre contraposiciones de estilos de vidas, reminiscencias de correspondencias y evocaciones de experiencias personales con algunos de los protagonistas, ubicarlos en un lugar merecido en la historia.

La crítica acuciosa del periodista saca a los poetas de esas líneas versadas, y los convierte en seres humanos tangibles, para que el lector sea capaz de palparlos, sentirlos, comprender sus motivaciones $y$, por ende, profundizar en las lecturas de sus versos.

Posteriormente, en 1986, recibe otro galardón, en ese mismo certamen, por su artículo "El caballo y su sombra". Este texto fue publicado en la tercera edición de la revista Unión de 1985 y está dedicado a la obra del poeta colombiano Miguel Ángel Osorio, más conocido entre sus lectores como Porfirio Barba Jacob.

\section{Resultado del análisis}

\section{de contenido}

Se encuentra dividido en seis subtítulos, en los cuales Suardíaz intercala de manera fluida anécdotas, pasajes de la vida de la personalidad, versos, referencias históricas, descripciones físicas, emocionales y una aguda reflexión con tono interrogante que nos acerca a un poeta sufrido e incomprendido por sus coetáneos.

Por eso, el periodista cita las opiniones que diversas figuras del orbe intelectual tenían acerca del enigmático Barba Jacob. Con precisión en el empleo de cada vocablo, economía en las palabras y claridad de las ideas, el texto es un válido acercamiento a toda la obra de este autor latinoamericano, donde el contexto sociohistórico en el cual vivió es enmarcado en cada una de las líneas del trabajo periodístico.

Y no se trata de un artículo en específico, generalmente, en sus textos valorativos con escasa frecuencia figuraban juicios acerca de determinado libro, género o corriente literaria en específico.

En su libro Sociología de la literatura, Robert Escarpit (1970) asegura:

... vemos que la comprensión del hecho literario - cualquiera que sea la modalidad por la cual lo 
abordemos- plantea problemas de psicología individual y colectiva. Una definición rigurosa de la literatura supone una convergencia de intenciones entre el lector y el autor; una definición más amplia exige al menos una compatibilidad de intenciones (p. 32).

Consciente de que la crítica literaria más aguda y sustancial estaba en abordar la vertiente biográfica de los juicios valorativos, al autor lo caracterizaba su inclinación por tratar la obra de un escritor en toda su magnitud, analizarla desde su nacimiento hasta la cúspide de su trabajo intelectual, que generalmente está pautado por la publicación de una gran obra literaria.

Por eso, se evidencian desde 1985 a 2005175 artículos referidos a autores. En la mayoría de los casos, más que cercanía profesional con alguna figura de las letras no solo cubanas, sino de talla universal, Suardíaz se caracterizaba por tener vínculos afectivos con los literatos. Este aspecto no matizaba su crítica de favoritismo hacia algún escritor en especial, su palabra era imparcial y, ante todo, llena de sentido y un olfato agudo del cual no debe prescindir texto periodístico alguno.
Lejos de entorpecer su trabajo, ese lazo amistoso que trazaba con sus colegas le proporcionaba a su crítica literaria un tono familiar; es decir, el lector no siente al autor que es analizado como alguien lejano, sino como un ser humano, motivado por experiencias de la vida y dotado con determinadas aptitudes creativas. En la obra de Suardíaz, imbricaba a la perfección el aspecto vivencial con el valorativo.

El vínculo afectivo con los escritores le permitió comprender y transmitir para un público medio las condiciones históricas sociales y las voluntades particulares que impulsaban al autor a hacerse eco, mediante determinado género literario, de sus criterios más personalizados.

Enfrascado en realzar la trayectoria literaria de algunos escritores que no han dejado una huella imperecedera en la historia, Suardíaz pone al descubierto la obra autoral tanto de literatos griegos como nigerianos.

Muchos de sus colegas destacan su capacidad para recordar con precisión las fechas; quizás esta habilidad le permitió referir en varios textos los aniversarios de nacimiento o muerte de algún autor, además de establecer, a partir de este criterio, puntos de contacto entre ellos. 
Figuran también, entre sus líneas críticas, ocho textos referidos a la literatura, en los cuales establece comparaciones entre los escritores de determinado país, estableciendo semejanzas y diferencias.

En estos textos, se puede observar la elevada cultura que poseía la personalidad en cuestión, al ser capaz de profundizar en la literatura, lo mismo de una región europea que americana.

En cuanto al libro, como modalidad literaria, se evidencian siete artículos en los que hace alusión a la publicación de alguna nueva edición. De esta manera, se evidencia una preponderancia de la modalidad literaria autoral, que persiste en ambos periodos.

Por su parte, los subgéneros literarios se comportan de la siguiente forma: 120 textos abordan aspectos relacionados con la poesía, en 15 se hace alusión a la novela y en 55 a ensayos históricos.

En el lenguaje empleado por Suardíaz para sus valoraciones literarias, primaba la primera persona y la mezcla de varios aspectos en un mismo tema, sin desviarse de la esencia del texto, lo cual le aportaba a sus artículos un nivel de argumentación excepcional.
Además, en sus textos persistía el estilo conversacional de su prosa, es decir, poseía cierto grado de erudición; sin embargo, no era pedante, al contrario, se tornaba asequible y criolla.

El dominio del idioma, el conocimiento de las reglas gramaticales, la originalidad, la unidad lógica y la fuerza expresiva son aspectos que se reflejan en cada una de las críticas literarias periodísticas de Suardíaz.

Era, ante todo, un observador de la cultura, de todo cuanto acontecía en el ámbito literario cubano, latinoamericano y universal. Por ello, en sus textos se exponen los valores genuinos de los creadores, sin llegar a la exaltación superflua e insustancial. Uno de sus trabajos más importantes fue encontrar en Cuba la novedad que significó el hallazgo del poema La Florida, como antecedente de Espejo de paciencia, investigación periodística que, por su importancia para la vida profesional de Suardíaz, no puede dejar de ser analizada en este trabajo de investigación (resultado del análisis de contenido)

Con argumentos sustentados en la Antología poética de los siglos XVII al XIX, de los intelectuales españoles Álvaro Salvador (Premio Casa de las Américas -2002-) y Ángel Esteban 
del Campo, Suardíaz refiere que los autores enriquecieron su obra con un aporte singular, pues:

... hallaron en la Biblioteca Nacional de España un extenso poema en octavas reales titulado La Florida, de un viajero peninsular nombrado Fray Escobedo. La primera parte de esta obra, con más de quinientos versos, describe su llegada a Baracoa y el viaje por la Isla -el paisaje, las costumbres, el carácter de las gentes-, y aunque no tiene, a juicio de los antólogos, la fuerza poética del poema de Silvestre de Balboa, es una crónica en octavas de importancia grande porque fue escrito entre 1598 y 1599, y de ese modo parece ser el primer texto literario escrito en la Isla y se inspira en ese momento de lento desarrollo social $(2002$, p. 3).

La anterior información aparece en el periódico, fechada el 19 de abril de 2002 y, como es de imaginar, suscitó polémica en el ámbito intelectual del país porque no hay nada más difícil que romper una tradición que ha sido acuñada, pero lo hizo con tal argumento que fue irrebatible.

Luego de su controversial publicación llamaron a algunos letrados a la recepción del periódico Granma para recriminar la falta de tacto del periodista; sin embargo, Suardíaz aplicó acertadamente la técnica del iceberg, tantas veces empleada por Hemingway, y no ofreció todos sus argumentos en un mismo artículo.

Así, más tarde entrevistó a los autores españoles para realzar la credibilidad de sus escritos, los cuales fueron publicados en varios medios de información nacional para masificar su lectura.

Luego circularon por revistas y periódicos ensayos referente al mismo tema, entre los que figuran: La Florida, ¿un poema cubano del siglo XVI?, Algo más sobre "La Florida" y también sobre el Espejo de... Balboa, Para una lectura parcial de "La Florida", y con argumentos más sólidos, lo cual demostraba el acierto de su investigación.

Crónicamente, Suardíaz evoca su reminiscencia del enigmático poema Espejo de paciencia, consciente del riesgo que incluye rebatir una verdad sustentada a través de siglos de investigación intelectual, "nací y crecí oyendo hablar de Espejo... con orgullo local", es decir, también él se incluye en el grupo de las personas “asombradas" tras el enigmático descubrimiento literario.

Otro aspecto de gran relevancia en la obra crítica literaria de Suardíaz 
es la referencia cronológica que persiste en cada uno de sus artículos; él siempre estaba al tanto de las efemérides de mártires, patriotas, escritores o artistas de relieve, así como de los hechos históricos más importantes acaecidos en el ámbito nacional.

Los elementos que distinguen la labor periodística de Luis Suardíaz Rivero como crítico literario pueden esbozarse a través de su estilo sencillo y ameno, la objetividad y la agudeza de cada uno de sus trabajos, así como por la sinceridad de estos.

Consecuente con su accionar, el propio Suardíaz, en una entrevista que le hiciera el periodista Fernando Rodríguez Sosa para la revista Revolución y Cultura, aseveró:

... el crítico no es un regañón ni un señor cargado de amarguras y portador de puñales envenenados o un payaso que aplaude todo el tiempo y habla de bondades que no existen a través de su bocina de cartón, sino un trabajador científico, un animador cultural.

La ejemplaridad de su crítica literaria, más allá de quedar perpetuada en sus merecidos premios nacionales de periodismo, persiste en la memoria de sus lectores y radioyentes, en sus experiencias literarias, cada vez más enriquecidas con la publicación o salida al aire de esos argumentos que lanzan a la lectura desenfadada y aguda.

\section{Discusión}

Esta investigación permite la caracterización de la labor periodística de Luis Suardíaz en medios impresos, durante el periodo 1959-2005, mostrando su quehacer en dos etapas fundamentales: de 1959 a 1983, cuando comienza su formación profesional, y de 1984 a 2005, que se puede considerar como un periodo de madurez; así lo confirman la obtención, en esa etapa, de dos premios nacionales de crítica literaria, el Premio de Periodismo Cultural Juan Gualberto Gómez y el Premio Nacional de Periodismo José Martí.

Los elementos que distinguen la labor periodística de Luis Suardíaz Rivero como crítico literario pueden estudiarse a través de los géneros y las modalidades literarias que analizó y por los recursos estilísticos que caracterizan sus textos.

En ambos periodos, se evidencia un predominio de redacción de críticas literarias relacionadas con la modalidad literaria del autor, 181 artículos y 126 textos que abordan 
elementos correspondientes con el subgénero poesía.

Las categorías analíticas utilizadas permitieron realizar una caracterización de la labor del periodista camagüeyano Luis Suardíaz Rivero, obteniéndose una información valiosa sobre su vida, lo cual demuestra la potencialidad de este método en estudios históricos de corte comunicológico.

\section{Referencias bibliográficas}

Alonso, M. y Saladrigas, H. (2012). Para investigar en comunicación social. Guía didáctica. La Habana: Pablo de la Torriente.

Álvarez, L. y Ramos, J. F. (s. f.). Circunvalar el arte. Santiago de Cuba: Editorial Oriente.

Araújo, C. (1989). El rol del periodista. La Habana: Pablo de la Torriente.

Araújo, N. y Delgado, T. (2001). Textos de teoría y crítica literaria. De formalismo a los estudios poscoloniales (I). La Habana: Félix Varela.

Baptista, P. L.; Hernández, C. C. y Hernández, R. S. (2010). Metodología de la investigación. La Habana: Pablo de la Torriente.
Barnet, M. (1966). Biografía de un cimarrón. La Habana: Academia de Ciencias de Cuba.

Barnet, M. (1989). La vida real. La Habana: Letras Cubanas.

Bertaux, D. (1989). Los relatos de vida en el análisis social. Historia y fuente oral. Barcelona: Sociedad Anónima.

Cámara, M. (1988). Cuadernos de periodismo. Por una nueva crítica. La Habana: Pablo de la Torriente.

Carpentier, A. (1975). El periodista, un cronista de su tiempo. En Granma, La Habana.

Cuesta, J. (1996). De la memoria a la historia. Entre el pasado y el presente. Historia y memoria. Madrid: Sociedad Anónima.

Escarpit, R. (1970). Sociología de la literatura. La Habana: Cuadernos de Arte y Sociedad.

Fallaci, O. (1991). Entrevista con la historia. La Habana: Pablo de la Torriente.

Folguera, P. (1990) ¿Cómo se hace la historia oral? Barcelona: Sociedad Anónima. 
Frye, N. (2001). Northrop Frye's Fearful Symmetry: A Study of William Blake (Vol. 14). University of Toronto Press.

Gargurevich, J. (1989). Géneros periodísticos. La Habana: Félix Varela.

Hudec, V. (1988). El periodismo: esencia, funciones sociales, desarrollo. Santiago de Cuba: Editorial Oriente.

Kerlinger, F. N. (1986). Foundations of behavioral research. New York, NY: Holt, Rinehart, and Winston.

S.A. La historia y el oficio del historiador (1996). La Habana: Editorial Ciencias Sociales.

Mallimaci, F. y Jiménez, V. (2006). Historia de vida y método biográfico. En Estrategias de investigación cualitativa. Barcelona: Gedisa.

Manuel, S. (2005). La crítica literaria en la universidad y en el periodismo. Recuperado de: http://manueljofre. blogspot.com/2005/08/la-critica-literaria-en-la-universidad.html

Marx, C. (1852). El Dieciocho Brumario de Luis Bonaparte. Moscú: Progreso.
Meneses Jiménez, M. T., y Cano Arana, A. (2008). Técnicas conversacionales para la recogida de datos en investigación cualitativa: La historia de vida (I i II). Nure Investigación, 37.

Mills, C. (1969). La imaginación sociológica (2. ${ }^{\mathrm{a}}$ ed.). La Habana: Revolucionarias.

Morales, J. et al. (2007). Psicología social (3. ${ }^{a}$ ed.). Madrid: Sociedad Anónima.

Morin, E. (2000). Cultura y conocimiento. En P. Watzlawick y P. Krieg P., El ojo del observador (p. 19). Barcelona: Gedisa.

Ochoa, J. (1996). Las historias de vida: un balcón para leer lo social. Revista Razón y Palabra, 5, 9.

Pérez, G. y Nocedo, I. (1983). Metodología de la investigación pedagógica y psicológica. La Habana: Pueblo y Educación.

Pérez, L. (2008). La crítica literaria sobre la narrativa cubana de los años 80 en la Gaceta de Cuba. Cuba. Trabajo de grado (Licenciatura en Periodismo), Universidad de La Habana. 
Plasencia, A. y Recio, M. (1999). El método biográfico. En Metodología de la investigación cualitativa. La Habana: Editorial Caminos.

Plejanov, J. (1959). El papel del individuo en la historia. Buenos Aires: Intermundo.

Prada, P. (2001). En busca del grial cubano. Periodismo vs. desmemoria: una propuesta. La Habana: Pablo de la Torriente.

Rodríguez, G. (2008). Metodología de la investigación cualitativa. La Habana: Félix Varela.

Rodríguez, J. (2007). El periodismo cultural en el Suplemento Cultural de la TVC. Cuba. Trabajo de grado (Licenciatura en Periodismo), Universidad de La Habana.

Santos, J. (2011). Siempre se vuelve a Camagüey. Camagüey: Ácana.

Suardíaz, L. (1985). El caballo y su sombra. Unión, 3, 85-106.
Suardíaz, L. (2005). La Florida, ¿un poema cubano del siglo XVI? Revista de la Biblioteca Nacional José Martí, 1-2, 86-92.

Taylor, S. y Bogdan, R. (2002). Introducción a los métodos cualitativos de investigación. Barcelona: Paidós.

Timoféiev, L. (1979). Fundamentos de la teoría de la literatura. Moscú: Progreso.

Vera, A. (2000). Pensamiento y tradiciones populares: estudio de identidad cultural cubana y latinoamericana. La Habana: Centro de Investigaciones y Desarrollo de la Cultura Cubana Juan Marinello.

Vivaldi, G. (1973). Géneros periodísticos. Madrid: Paraninfo.

Wolf, M. (2005). La investigación en la comunicación de masas. La Habana: Pablo de la Torriente.

Zurbano, R. (2007). Narrar la crítica. El Cuentero, 5, 2-5. 